\title{
How to Reform the FDA
}

The chief recommendations of the Ritts committee concern the setting up of a system of science advisory committees to give scientists a more powerful say in the agency's affairs and to correct the predominance given to compliance branches of the agency over the scientific branches. The committee recommends that each of the four bureaus of the FDA should be guided by a National Advisory Council including scientists versed in the relevant disciplines as well as representatives of community and consumer interests. Scientific Review Committees should be established to advise on continuing problems, such as screening applications to market new drugs, and ad hoc scientific advisory committees should be created to deal with particular issues. An in-house Scientific Planning Committee should be set up consisting of the heads of bureaus and the associate commissioners for science and medical affairs.

In studying the present FDA programme of awarding research contracts, the committee found that "serious deficiencies exist at all levels of the process". Its suggested remedies-which have been accepted in principle or already effectedinclude such elementary advice as giving the widest possible publicity to the contract programme so that every interested scientist has an opportunity to apply, appointing full time project managers to ensure the purposes of the contract are met, and having contracts reviewed by the proposed Scientific Review Committees.

The 17 district offices of the FDA (of which the committee visited 12) handle responsibilities that are "literally overwhelming" and can do no more than spot check the food and drugs entering the market. As a result an appreciable number of marketed drugs - 25 per cent according to some studies-are substandard. The committee recommends that drug certification should be transferred from the district laboratories and centralized in a National Center for Drug Certification to be established by the FDA. Meanwhile the district offices should become more specialized, their facilities improved, and their work made more generally known in order to develop a favourable public constituency.
Turning to the four bureaus of the FDA, the Ritts committee recommends that the Bureau of Veterinary Medicine be incorporated into the other three bureaus of the agency since the purported uniqueness of veterinary drugs does not justify its separate existence. The veterinary research division of the Bureau, for which the committee has high praise, could form the basis of a new drug research group in the Bureau of Drugs. These suggestions, which Edwards has interpreted as a "recommendation to abolish the present Bureau" have already been rejected by the FDA for reasons that are unapparent.

The Bureau of Foods, already undergoing a major reorganization, nevertheless suffers from most of the general criticisms of science management, and indeed was the source of many of them. The only bureau laboratory studied by the Ritts committee, the National Center for Microbiological Analysis at Minneapolis, is understaffed and so badly managed that the committee failed to identify any "discernible method by which important research problems in microbiology are identified. . . . The committee concurs that NCMA is largely a series of existing job slots". The laboratory should be abolished and its functions assumed by the Office of Food Hygiene and Sanitation. The committee lists a series of projects which the laboratory should have been studying and which are presumably at present being neglected by the FDA, including such basic questions as the relationship between bacterial $\mathbf{R}$ factors and antibiotics in animal feeds, and the contamination of foods and drugs with viruses.

The committee finds that the Bureau of Drugs is "not yet meeting all of [its] objectives in an ideal manner" but that there is no reason why the bureau cannot develop "in this decade" into an efficient and professional organization. The committee recommends the bureau strengthen its scientific staff, particularly in the area of statistics and epidemiology, so that its laboratories "would be in a position to confirm or extend data supplied by manufacturers and investigators". The bureau should establish a National Drug Experience Reporting System with a view to learning about the effect of drugs on the population. The Commissioner should ask Congress for legal authority to compel the drug companies to let the FDA know what drugs they are putting on the market and in what quantities.

The committee is particularly critical of the way in which the Bureau of Drugs handles one of its most important functions. the review of applications to put new drugs on the market. Suggested remedies are that the FDA medical officers who "all too often [have] neither research experience nor prestige among [their] scientific peers", be upgraded by receiving better training, better support from the administrative hierarchy of the agency, and the support of a pharmacologist, a chemist and a statistician in the review of new drug applications.

In conclusion, the Ritts committee summarizes its recommendations as a demand for "better central science planning, increased participation of scientists in this planning, improved management and communication practices throughout the agency, wider use of extramural scientists on councils and committees, improved review and management procedures for grants and contracts, increasing specialization and regionalization of the district laboratory operation ... development of improved training and management procedures for the review of protocols in the Bureau of Drugs, and a general call for an agency-wide attitude which understands that good science is the fundamental basis for effective decision-making by a consumer protection agency in our complicated technological society. . . Finally, the committee feels that the FDA is not well understood. Long battered in public-by industry, by the medical profession, by the press and all too often by itself-the FDA is now without the broad base of public support a health-oriented consumer protection agency ought to enjoy in our society. . . . The committee believes that a valuable by-product of a more open relationship between the FDA and extramural scientists could well be a broader base of support in the scientific establishment. For similar reasons, the FDA has much to gain from a high quality, imaginative approach to consumer education". 